\title{
Sample and comparison location as factors in matching acquisition, transfer, and acquired equivalence
}

\author{
Peter J. Urcuioli \\ Purdue University, West Lafayette, Indiana
}

\begin{abstract}
Pigeons learned symbolic matching with samples appearing equally often on left and right keys. For a location-relevant group, the reinforced comparison choice for each sample reversed across sample locations; for a location-irrelevant group, the reinforced choices were the same. Consistent with the hypothesis that samples at different locations are functionally different for pigeons, Experiment 1 showed that matching acquisition was comparable in these two groups. Nevertheless, the location-irrelevant group eventually ignored sample location, given that their performances subsequently transferred to a novel (center-key) sample location. This transfer was not simply due to sample familiarity at different training locations; rather, it required that left- and right-key samples occasion the same reinforced choices in training. Acquired equivalence between those samples was then assessed in Experiment 2. The location-irrelevant group showed the predicted equivalence effects, but the location-relevant group did not — in fact, its results were the opposite of those predicted by equivalence. Their results indicate that the functional comparison stimuli are also defined in terms of their locations.
\end{abstract}

Previous research has shown that location is a controlling feature of the nominal conditional and discriminative stimuli in tasks such as matching-to-sample (Iversen, 1997; Iversen, Sidman, \& Carrigan, 1986; Lionello \& Urcuioli, 1998). For instance, Lionello and Urcuioli (1998) trained pigeons to high levels of accuracy on twosample, two-comparison matching tasks with a typical configuration of stimuli: samples on the center key and comparison stimuli on the adjacent (left and right) side keys. When pigeons were later tested with the familiar samples appearing on one or the other side key and the familiar comparisons appearing on the remaining two keys, performances were close to chance (50\% accuracy). The pigeons' inability to maintain accurate matching performances when samples and comparisons appeared at novel locations (or combinations of locations) was striking. Perhaps even more striking was the finding that accurate matching was not maintained with shifts in stimulus location even when pigeons had prior experience with other conditional and discriminative stimuli that appeared in a variety of locations during training (Lionello \& Urcuioli, 1998, Experiment 3). Thus, experience per se with sample and comparison stimuli at different key locations was insufficient to support location-independent matching with other samples and comparisons.

Location, then, clearly matters for pigeons despite its being (from the experimenter's perspective) an incidental stimulus. Obviously, this feature is not incidental from the pigeon's perspective (cf. McIlvane, Serna, Dube,
\& Stromer, 2000): For them, the functional stimuli appear to be what it sees and where it sees it. Thus, in a standard identity task with red and green hues (see, e.g., Cumming \& Berryman, 1961), pigeons do not simply learn to match "red to red" and "green to green," but "red-on-the-left-key to red-on-the-center-key," "greenon-the-left-key to green-on-the-center-key," and so on. One reason for this, perhaps, is that reinforcement is correlated equally well with stimuli whose functional definition includes their location as with the nominal stimuli themselves. Moreover, given that location is a salient dimension for pigeons (see, e.g., Bowe, Miller, \& Green, 1987; Urcuioli, 2006b; Urcuioli, Vu, \& Proctor, 2005; Wilkie, Jacobs, \& Takai, 1985), perhaps it should not be surprising that pigeons would attend to it even though it is unnecessary to do so (cf. Jenkins \& Harrison, 1960; Williams, Butler, \& Overmier, 1990).

The impact of stimulus location on matching performance can be diminished if pigeons are explicitly trained to match samples and comparisons independently of their location. For example, Lionello-DeNolf and Urcuioli (2000, Experiments 1 and 2) ran a matching task in which the samples appeared on the left key on some trials and on the right key on other trials (with the comparisons appearing on the remaining keys). After pigeons acquired this task to high levels of accuracy, they continued to match accurately when the samples appeared for the first time at a new location - namely, the center key. Nevertheless, accuracy on these novel-location test trials was typically not

P. J. Urcuioli, uche@psych.purdue.edu 
as high as that on the baseline trials, pointing once again to the potency of stimulus location.

The present experiments tested two implications of the role of stimulus location in pigeons' matching performances. First, if a stimulus at one location is (at least initially) a functionally different stimulus than the same stimulus at a different location, then matching acquisition should be no less rapid if the reinforced comparison choice for a given sample reverses across sample locations than if it is the same. Such a null result typically creates interpretive problems. However, one ought to expect that learning a set of conflicting sample-comparison contingencies would be more difficult than learning a set of congruent contingencies (see, e.g., Peterson \& Trapold, 1982; Urcuioli, DeMarse, \& Lionello-DeNolf, 2001, Experiment 1). Consequently, a failure to obtain slower acquisition when each sample occasions the opposite choice across locations should be surprising and theoretically noteworthy.

Second, training with conflicting contingencies raises the interesting possibility of acquired sample equivalence between different hues at different locations. For example, if a red sample on the left key occasions the same reinforced choice as a green sample on the right key, would left-red and right-green become members of the same acquired equivalence class (Urcuioli, 1996)? If so, this result would be an especially powerful demonstration of how occasioning a common reinforced response can bring disparate stimuli together into a class (Urcuioli, 2006a; Urcuioli \& Lionello-DeNolf, 2005).

\section{EXPERIMENT 1}

In Experiment 1, pigeons learned to match vertical- and horizontal-line comparisons to red and green samples that appeared on either the left or right key. For the locationrelevant group, reinforced choices reversed across the left and right sample locations so that if pecking the vertical line was reinforced when the red sample appeared on the left key, then pecking the horizontal line was reinforced when red appeared on the right key, and vice versa for the

Table 1

Symbolic Matching Contingencies in Experiment 1

\begin{tabular}{|c|c|c|c|c|}
\hline \multirow[b]{2}{*}{ Group } & \multicolumn{2}{|c|}{ Sample } & \multirow[b]{2}{*}{ Comparison 1} & \multirow[b]{2}{*}{ Comparison 2} \\
\hline & Left Key & Right Key & & \\
\hline \multirow{4}{*}{$\begin{array}{l}\text { Location } \\
\text { relevant }\end{array}$} & $\mathrm{R}$ & - & $\mathrm{V}+$ & $\mathrm{H}-$ \\
\hline & $\mathrm{G}$ & - & $\mathrm{V}-$ & $\mathrm{H}+$ \\
\hline & - & $\mathrm{R}$ & $\mathrm{V}-$ & $\mathrm{H}+$ \\
\hline & - & G & $\mathrm{V}+$ & $\mathrm{H}-$ \\
\hline \multirow{4}{*}{$\begin{array}{l}\text { Location } \\
\quad \text { irrelevant }\end{array}$} & $\mathrm{R}$ & - & $\mathrm{V}+$ & $\mathrm{H}-$ \\
\hline & $\mathrm{G}$ & - & $\mathrm{V}-$ & $\mathrm{H}+$ \\
\hline & - & $\mathrm{R}$ & $\mathrm{V}+$ & $\mathrm{H}-$ \\
\hline & - & G & $\mathrm{V}-$ & $\mathrm{H}+$ \\
\hline \multirow{4}{*}{ Control } & $\mathrm{R}$ & - & $\mathrm{V}+$ & $\mathrm{H}-$ \\
\hline & G & - & $\mathrm{V}-$ & $\mathrm{H}+$ \\
\hline & - & $\mathrm{R}$ & $\mathrm{B}+$ & W- \\
\hline & - & G & $\mathrm{B}-$ & $\mathrm{W}+$ \\
\hline
\end{tabular}

Note- $\mathrm{R}$, red; G, green; B, blue; $\mathrm{W}$, white; V, vertical lines; $H$, horizontal lines; + , reinforced choice; - , nonreinforced choice. green sample (see Table 1). By contrast, the reinforced line-comparison choices were the same across locations for the location-irrelevant group. Rates of acquisition for these two groups were of interest in this initial experimental phase.

A novel-location test followed acquisition. In this test, periodic probe trials in which red and green appeared on the center key and vertical and horizontal lines appeared on the adjacent side keys were intermixed among baseline (left- and right-sample) matching trials. The purpose of the test was to confirm that the location-irrelevant group learned to ignore sample location and would thus transfer their performances to a novel, center-key sample location (Lionello-DeNolf \& Urcuioli, 2000). To assess the training conditions necessary to produce this expected transfer, an additional control group was included in Experiment 1. This group learned to match entirely different comparisons to the left- and right-key samples. Specifically, they matched vertical and horizontal lines to red and green samples on the left key, but blue and white hues to red and green samples on the right key. At issue was whether familiarity with red and green at two different training locations would be sufficient to produce transfer of the (nonconflicting) hue-line performances to the novel, center-key sample location.

\section{Method}

\section{Subjects}

Twenty-four White Carneau retired breeders from the Palmetto Pigeon Plant (Sumter, SC) were randomly divided into three groups of 8 . Each group had 4 experimentally naive pigeons and 4 pigeons with prior experience on unrelated simultaneous discriminations. All were housed individually in stainless-steel, wire-mesh cages in a temperature- and humidity-controlled colony room on a 14:10-h light:dark cycle, with lights on at 07:00. Pigeons were maintained at $80 \%$ of their free-feeding body weights by restricting feeding to the experimental sessions (except for the 1 day a week on which the experiment was not run). Grit and water were freely available in the home cage. One pigeon was replaced when it became ill during the study.

\section{Apparatus}

Two identically configured BRS/LVE (Laurel, MD) chambers (Model PIP-016 panels inside Model SEC-002 enclosures) were used. The three $2.5-\mathrm{cm}$ circular response keys on the panels were spaced $8.3 \mathrm{~cm}$ apart, center-to-center, and aligned in a horizontal row that was $25 \mathrm{~cm}$ above the grid floor. Mounted behind each key was a BRS/LVE stimulus projector (Model IC-901-IDD) that could display red, green, blue, and white homogeneous fields, and three white vertical and three white horizontal lines on black backgrounds (BRS/ LVE Pattern No. 692). A 5.8-cm-wide $\times 5.0$-cm-high opening that was $13 \mathrm{~cm}$ below the center key provided access to a back-mounted food hopper that delivered Purina Pigeon ProGrains. When raised, the hopper was illuminated by a 28-ESB miniature bulb. General chamber illumination was provided by a shielded General Electric 1829 bulb whose light was directed toward the ceiling. Masking noise and ventilation were provided by continuously running blower fans mounted on each enclosure. Experimental events were controlled and monitored by IBM-compatible 386 computers. Equal numbers of pigeons from each group were run in each chamber.

\section{Procedure}

Preliminary training. The experimentally naive pigeons were initially trained to eat quickly and reliably from a raised and lit 
food hopper, after which the keypeck response to a small white dot on the center key was shaped by the method of successive approximations.

Next, all pigeons were trained to obtain food by pecking red and green on the left and right keys. The number of pecks necessary to obtain food was gradually raised from 1 to 10 over 10 sessions, each of which contained 60 trials divided equally among four possible combinations of hues and key locations. Trials began when one side key was illuminated with either red or green. Completing the scheduled fixed ratio immediately turned off that stimulus and produced food. A 10 -sec intertrial interval (ITI), during the first $9 \mathrm{sec}$ of which the house light was off, then ensued. Food reinforcement durations were constant within a session, but varied from 2-6 sec across birds and sessions to maintain each pigeon's body weight at $80 \%$ of its free-feeding value.

During the last two 60-trial preliminary training sessions, single pecks to vertical and horizontal lines or to blue and white hues were reinforced. The two stimuli for each session were shown equally often on the left, center, and right keys, with successive trials separated by 10 -sec ITIs.

Symbolic matching acquisition. Acquisition of 0-delay symbolic matching-to-sample began following preliminary training. Each matching session consisted of 96 trials divided equally among the 8 possible trial types $(2$ samples $\times 2$ locations per sample $\times$ 2 positions of the comparison alternatives) that occurred in random order, with the constraint that none occur more than twice in a row. Trials began with either red or green appearing on the left or right key. Ten pecks to the hue sample immediately turned it off and produced the comparisons on the remaining keys. Vertical and horizontal lines appeared as comparisons on all trials for the location-relevant and location-irrelevant groups. For the control group, vertical and horizontal comparisons appeared after left-key samples, but blue and white comparisons appeared after right-key samples. For all groups, a single peck to either comparison turned both off and produced either food or an equally long timeout with the house light turned off, depending on whether the choice was correct or incorrect, respectively. Successive matching trials were separated by a 10 -sec ITI, the first $9 \mathrm{sec}$ of which was spent in darkness. The house light came on for the last $1 \mathrm{sec}$ of the ITI and remained on throughout the subsequent trial.

For the location-relevant group, the reinforced line-comparison choices reversed across sample locations. Thus, if vertical and horizontal choices were reinforced following left-key red and green samples, respectively, then horizontal and vertical choices were reinforced following right-key red and green samples, respectively (see Table 1). These contingencies were counterbalanced across the birds in this group. For the location-irrelevant group, choosing vertical- and horizontal-line comparisons, respectively, was always reinforced following the red and green samples (i.e., independently of sample location) for half of the birds, and vice versa for the other half. For the control group, the left sample-line comparison contingencies and right sample-hue comparison contingencies were arranged so that all possible combinations of contingencies were equally represented across birds.

Each pigeon was trained on its respective task until overall accuracy was $90 \%$ correct or better and accuracy for each sample location was $87.5 \%$ correct or better, for 5 of 6 consecutive sessions. If these performance criteria had not been achieved by the 20th session, training either continued as described (if performances were improving or nearing criterion), or a correction procedure (in which an incorrect choice on any matching trial repeated that trial) was implemented. The correction procedure remained in place until overall and left- and right-sample accuracies reached the aforementioned levels. At that point, noncorrection training resumed until the performance criteria were again met for 5 of 6 consecutive sessions. Four birds (two in the location-irrelevant group, one in the locationrelevant group, and one in the control group) required a correction procedure. For measurement purposes, the first session of criterion for these birds was the session in which the correction procedure was implemented.

Novel location tests. Once criterion levels of performance without a correction procedure were achieved, each pigeon received 10 location-test sessions. Each test session contained 80 baseline (leftand right-sample) trials and 16 trials in which the samples appeared on the center key and the line comparisons on the adjacent side keys. The four possible test configurations of samples and left-right positions of the comparisons occurred equally often in a session, with the restriction that at least 1 each of the 8 baseline trials occur prior to the first test trial.

All test-trial choices produced food. Baseline choices during testing, however, continued to be differentially reinforced according to each bird's matching contingencies. For the location-irrelevant and control groups, a "correct" test-trial choice was defined as pecking the same line-orientation comparison after red and green, as was reinforced on the baseline trials. For the location-relevant group, a vertical choice after red and a horizontal choice after green were arbitrarily designated as "correct." All other details were identical to those for training.

\section{Statistical Analyses}

Type I error rate for an ANOVA and for post hoc contrasts was set at .05 , using the tabled $F$ values provided by Rodger (1975). These tabled values control Type I error rate on a per-decision basis.

\section{Results}

Figure 1 summarizes the acquisition results for the location-irrelevant and location-relevant groups. This figure shows the average number of training sessions $(+1 S E M)$ reaching $90 \%$ overall accuracy (black bars) and $87.5 \%$ accuracy with left- and right-key samples (as labeled). Numerically, the location-irrelevant group reached $90 \%$ overall accuracy in fewer sessions (16.6; range: $6-51)$ than the location-relevant group (21.9; range: 11-51). The same was true for the number of sessions to reach $87.5 \%$ accuracy with the left-key samples (10.9 vs.

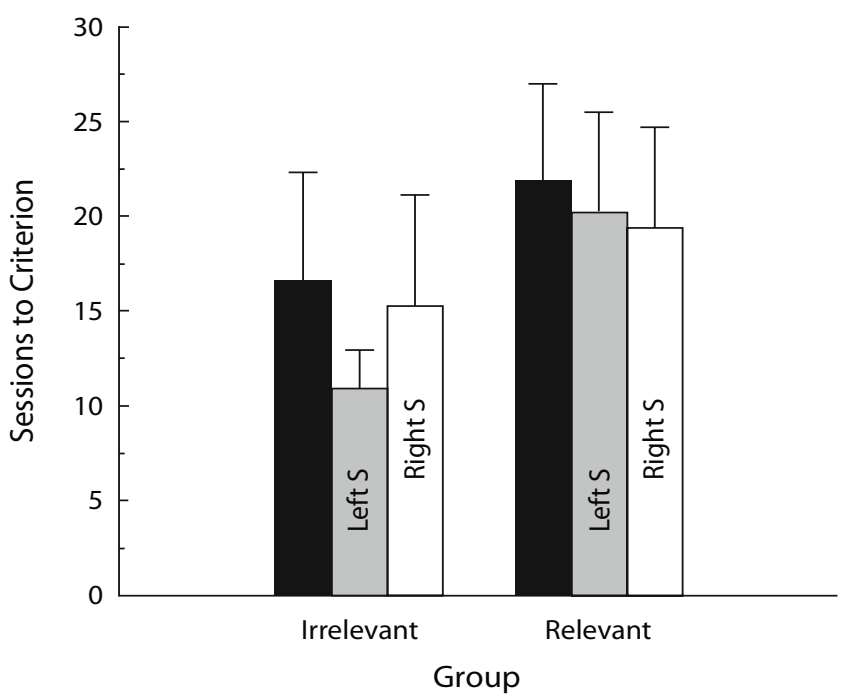

Figure 1. The number of sessions to criterion levels of accuracy $(+1 S E M)$ for irrelevant and relevant groups in Experiment 1. Sessions-to-criterion is shown for all matching trials (black bars) and for matching with left-key samples (Left $S$ ) and right-key samples (Right $S$ ). 
20.2 sessions, respectively) and right-key samples (15.2 vs. 19.4 sessions, respectively). However, an ANOVA showed no significant between-groups difference in any performance measure $\left[F_{\mathrm{s}}(1,14)=0.54,3.14\right.$, and 0.31 for overall, left-sample, and right-sample performances, respectively].

The control group, which saw different comparisons on left- and right-sample trials (see Table 1), achieved 87.5\% accuracy on the left-sample trials in 22.2 sessions (range: 5-47) and 18.6 sessions (range: 6-61) on right-sample trials. Sessions-to-criterion on left-sample trials did not differ significantly from the left-sample sessions-to-criterion in the location-irrelevant and location-relevant groups $[F(2,21)=1.86]$.

Additional analyses confirmed what the ANOVAs on the sessions-to-criterion results indicated. For example, matching accuracy over the five noncorrection criterion sessions did not differ significantly between groups. Mean accuracy on left-sample trials was $95.6 \%$ correct in the location-irrelevant group versus $94.6 \%$ correct in the location-relevant group; on right-sample trials, mean accuracy was $93.4 \%$ versus $93.3 \%$ correct, respectively $[F \mathrm{~s}(1,14)<2.30]$.

Figure 2 shows performances on the subsequent location tests averaged across blocks of five test sessions. On the nondifferentially reinforced center-sample test trials, the location-irrelevant group chose the same line comparisons that were reinforced on their baseline trials $70.5 \%$ and $69.2 \%$ of the time during the first and second block, respectively. By contrast, the control group showed accuracies close to chance: $57.8 \%$ and $52.3 \%$ during the first and second block, respectively. Finally, as expected - given that their reinforced line-comparison choices in training switched across sample locations - the location-relevant group chose each line comparison about equally often on the test trials.

An ANOVA on these data with group and test block as factors showed a significant group effect $[F(2,21)=$
6.88], no significant effect of block $[F(1,21)=2.67]$, and no significant group $\times$ block interaction $[F(2,21)=$ 1.03]. Post hoc, orthogonal contrasts showed no difference in test-trial accuracies in the control and locationrelevant groups $[F(2,21)=0.06]$. However, accuracy in the location-irrelevant group was significantly higher than that in the other two groups $[F(2,21)=6.82]$. In short, baseline matching performances transferred to the hue samples when they appeared on the center key only in the location-irrelevant group.

\section{Discussion}

Experiment 1 showed that ostensibly conflicting symbolic matching contingencies were learned as rapidly as congruent contingencies, and that asymptotic accuracies were comparable as well. These results are less surprising, however, on the assumption that in the absence of any special training (Lionello-DeNolf \& Urcuioli, 2000), a visual stimulus appearing at one location is a functionally different stimulus for pigeons than the same stimulus appearing at another location (Lionello \& Urcuioli, 1998). From this perspective, the left- versus right-sample contingencies for location-relevant group were not conflicting. This idea implies that its rate of acquisition and that of the locationirrelevant group should largely reflect the discriminability between the red versus green samples at each location and the discriminability between the vertical versus horizontal comparisons at their locations (Carter \& Eckerman, 1975; see also Urcuioli \& Zentall, 1986). Given the same nominal samples and comparisons for these two groups, there would be no discriminability differences between them, which should promote the comparable performances that were in fact observed.

Of course, the location-irrelevant group learned during training that sample location did not matter, and to attend only to sample hue (Lionello-DeNolf \& Urcuioli, 2000). The fact that their baseline performances transferred to the

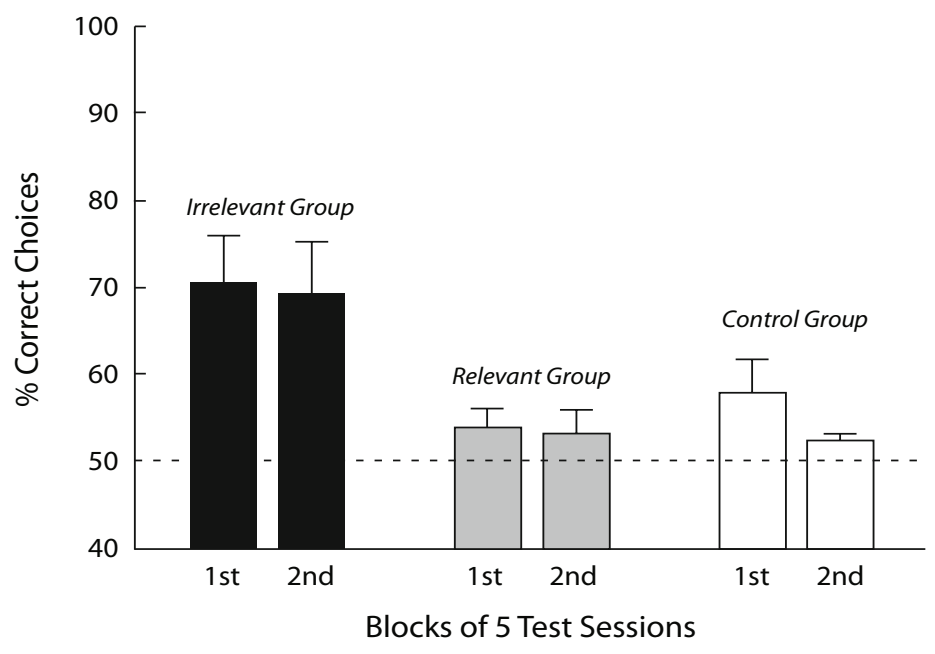

Figure 2. The percentage of correct choices $(+1 S E M)$ for each group on novel, center-key-sample trials over successive five-session blocks of location testing in Experiment 1. 
red and green samples when shown at a novel (center-key) location demonstrates this. But if these pigeons ignored sample location, only two rules were needed to support accurate performance (e.g., "choose vertical after red" and "choose horizontal after green") in comparison with four for the location-relevant group ("choose vertical after left-red," "choose horizontal after left-green," "choose horizontal after right-red," and "choose vertical after right-green"). So why didn't fewer rules produce faster learning as in other conditional discriminations (Berryman, Cumming, Cohen, \& Johnson, 1965)?

One answer is that acquisition rate depended on when sample location came to be ignored in training. Unfortunately, there was no direct way to assess this. However, if we assume that the earlier location was ignored, then the greater the control exerted by the nominal (red and green) samples (cf. Wagner, Logan, Haberlandt, \& Price, 1968), the transfer of that control to a novel sample location should be stronger for pigeons that learned the location-irrelevant task relatively quickly. Indeed, there was a negative correlation in this group between sessions-to-criterion and accuracy on the novel location test $(r=-.54, p=.16)$.

A better answer, however, is that changing sample location across trials slowed the rate at which the locationirrelevant birds learned their symbolic matching task. Pearce and Redhead (1993, Experiment 1), for example, showed that adding an irrelevant stimulus to the CS + and $\mathrm{CS}-$ of an autoshaping discrimination slowed the rate of learning in comparison with that occurring without an irrelevant stimulus. Some configural theories of learning (see, e.g., Pearce, 1987, 1994) predict this finding by assuming that an irrelevant stimulus increases the similarity between discriminative stimuli, thus reducing the rate of differentiation in their associative strengths. Here, the red and green samples would be analogous to the abovementioned discriminative stimuli, because they alone signaled the reinforced comparisons in the location-irrelevant group. The irrelevant stimulus was the left- versus rightkey location, given that the reinforced comparison did not change as a function of where sample stimulus appeared. If this left-right variation increased the similarity between red and green, then it would take longer for these samples to acquire substantial control over comparison choice than if they always appeared at a single location. Although no matching data speak directly to this issue, the pigeon autoshaping data make this account especially plausible.

This experiment also showed that symbolic matching performances with left- and right-key samples will transfer to a novel, center-key location, provided that each sample in training occasions the same reinforced choice. Specifically, pigeons matched accurately with red and green on the center key only if both the left-red and right-red samples occasioned the same line-comparison choice in training, and if both the left-green and rightgreen samples did likewise. This replicates the findings of Lionello-DeNolf and Urcuioli (2000). More importantly, transfer did not occur when pigeons made entirely different comparison choices following left- and right-key samples in training (e.g., by choosing a line comparison after a left-red sample, but a hue comparison after a rightred sample). The chance level of test performance by the control group demonstrates this. Together, the test results show that familiarity of seeing the samples at different locations during training is not sufficient by itself for those samples to support accurate matching when shown at a novel location.

\section{EXPERIMENT 2}

Experiment 2 was designed to test for a potentially dramatic effect in the location-relevant group. Specifically, given that the nominally opposing hue samples (e.g., red on the left key and green on the right key) occasioned the same reinforced choice (e.g., vertical lines) during many-to-one training in this group, did these samples become members of an acquired equivalence class? Previous research (e.g., Urcuioli, Zentall, Jackson-Smith, \& Steirn, 1989; Wasserman, DeVolder, \& Coppage, 1992; see also Grant \& Spetch, 1993; Urcuioli, 2006a) demonstrates that common choice associations will produce acquired sample equivalence but, typically, the samples in question are drawn from different stimulus dimensions or categories. Here, they were from the same (hue) dimension, and nominally, each would theoretically belong to two separate equivalence classes, [Left-Red, RightGreen] and [Right-Red, Left-Green].

However, this acquired equivalence effect was not obtained. Indeed, the test results for the location-relevant group in this experiment were precisely the opposite of what would be expected on the basis of [Left-Red, RightGreen] and [Right-Red, Left-Green] classes. As will be explained more fully in the General Discussion, the results point to the necessity of defining "common choices" with reference to comparison location. Furthermore, familiarity of seeing particular comparisons at particular locations in testing is also important.

In any event, Table 2 shows a schematic of the acquired equivalence test procedure. Comparison location has been purposely omitted in order to convey what was initially regarded as the reinforced choices. The left column shows the initial training that each group received in Experiment 1; only the reinforced comparisons are depicted (cf. Table 1). The lines for the location-relevant and location-irrelevant groups connect samples that ostensibly occasioned the same reinforced choice. For example, for the location-relevant group, the L(eft) Red and $\mathrm{R}$ (ight) Green samples are connected, as are the L(eft) Green and R(ight) Red samples, because these were associated with the reinforced V(ertical) and H(orizontal) line choices, respectively. To assess acquired equivalence between such samples, Experiment 2 initially arranged reassignment training (Wasserman et al., 1992) with just the right-key samples. In other words, R Red and R Green were established as conditional cues for new comparison choices, $\mathrm{B}($ lue) and $\mathrm{W}$ (hite). After reassignment, pigeons were then tested on their abilities to match the B and W comparisons to the remaining left-key samples.

The choices in testing that are indicative of acquired sample equivalence are underlined. The logic is as follows. 
Table 2

Procedure for Testing Acquired Sample Equivalence in Experiment 2

\begin{tabular}{|c|c|c|c|c|c|}
\hline Group & \multicolumn{2}{|c|}{ Initial Training } & Reassignment & \multicolumn{2}{|r|}{ Testing } \\
\hline $\begin{array}{l}\text { Location } \\
\text { relevant }\end{array}$ & $\begin{array}{l}\text { L Red } \\
\square \text { L Green } \\
- \text { R Red } \\
\text { R Green }\end{array}$ & $\begin{array}{l}\rightarrow \mathrm{V}+ \\
\rightarrow \mathrm{H}+ \\
\rightarrow \mathrm{H}+ \\
\rightarrow \mathrm{V}+\end{array}$ & $\begin{array}{l}\text { R Red } \rightarrow \mathrm{B}+ \\
\text { R Green } \rightarrow \mathrm{W}+\end{array}$ & $\begin{array}{l}\text { L Red } \\
\text { L Green }\end{array}$ & $\begin{array}{l}\rightarrow \mathrm{B} \text { versus } \underline{\mathrm{W}} \\
\rightarrow \underline{\mathrm{B}} \text { versus } \mathrm{W}\end{array}$ \\
\hline $\begin{array}{l}\text { Location } \\
\text { irrelevant }\end{array}$ & $\begin{array}{l}\text { L Red } \\
\text { L Green } \\
\text { R Red } \\
\text { R Green }\end{array}$ & $\begin{array}{l}\rightarrow \mathrm{V}+ \\
\rightarrow \mathrm{H}+ \\
\rightarrow \mathrm{V}+ \\
\rightarrow \mathrm{H}+\end{array}$ & $\begin{array}{l}\text { R Red } \rightarrow \mathrm{B}+ \\
\text { R Green } \rightarrow \mathrm{W}+\end{array}$ & $\begin{array}{l}\text { L Red } \\
\text { L Green }\end{array}$ & $\begin{array}{l}\rightarrow \underline{\mathrm{B}} \text { versus } \mathrm{W} \\
\rightarrow \mathrm{B} \text { versus } \underline{\mathrm{W}}\end{array}$ \\
\hline Control & $\begin{array}{l}\text { L Red } \\
\text { L Green } \\
\text { R Red } \\
\text { R Green }\end{array}$ & $\begin{array}{l}\rightarrow \mathrm{V}+ \\
\rightarrow \mathrm{H}+ \\
\rightarrow \mathrm{B}+ \\
\rightarrow \mathrm{W}+\end{array}$ & - & $\begin{array}{l}\text { L Red } \\
\text { L Green }\end{array}$ & $\begin{array}{l}\rightarrow \mathrm{B} \text { versus } \mathrm{W} \\
\rightarrow \mathrm{B} \text { versus } \mathrm{W}\end{array}$ \\
\hline
\end{tabular}

Note—L, left; R, right; V, vertical lines; H, horizontal lines; B, blue; W, white; +, reinforced comparison. Connected lines under "Initial Training" group together samples associated with the same reinforced comparison. Underlining under "Testing" denotes comparison choices predicted by acquired sample equivalence.

If initial training established L Red and R Green samples as members of one class and L Green and R Red samples as members of another class for the location-relevant group, and if these pigeons have now learned to select the blue comparison after $\mathrm{R}$ Red and the white comparison after $\mathrm{R}$ Green, then on test trials, they should prefer the blue comparison after L Green and the white comparison after L Red. In other words, after each nominal left-key sample in testing, the location-relevant pigeons should "do the opposite" relative to the reinforced choice they made after each nominal right-key sample in reassignment.

The logic is similar for the location-irrelevant group, although the prediction here is that pigeons should prefer the same comparison after each left-key sample in testing that had been reinforced after the same nominal sample in reassignment (e.g., if the blue choice was reinforced after $\mathrm{R}$ Red on reassignment trials, then pigeons should prefer blue after L Red in testing).

Finally, preference for the blue versus white comparisons could also be tested without separate reassignment training in the control group, because these pigeons had learned to select those comparisons on right-key sample trials during initial training in Experiment 1. Obviously, since left and right samples in this group were initially associated with different comparisons, any blue versus white comparison preferences in testing could only arise via generalization between the right and left sample hues.

Test trials for all groups were conducted with differential reinforcement in order to avoid rapid extinction. Consequently, to distinguish between test performances that reflect prior training as opposed to new learning on the test trials themselves, each group was split into consistent and inconsistent subgroups (not shown in Table 2). Unlike the manner in which these terms are typically used (cf. Urcuioli et al., 1989; Urcuioli \& Lionello-DeNolf, 2001), in the present article, consistent and inconsistent were defined by reference to nominal red and green samples (in order to accommodate the control group). Thus, if the blue comparison was matched to the red sample and the white comparison was matched to the green sample when those samples appeared on the right key, then the consistent test meant reinforcing blue after red and white after green when those samples appeared on the left key. Conversely, the inconsistent test involved reinforcing the opposite choices (viz., white after red and blue after green).

If initial training for the location-relevant group yielded [Left-Red, Right-Green] and [Left-Green, Right-Red] sample classes, then test-trial accuracies should be higher in the inconsistent than in the consistent condition. In other words, these pigeons should prefer the W(hite) comparison after the $\mathrm{L}(\mathrm{eft}) \mathrm{Red}$ sample in testing even though the alternative $\mathrm{B}$ (lue) choice had been reinforced after the R(ight) Red sample in reassignment. Likewise, they should prefer the B(lue) comparison after the $\mathrm{L}(\mathrm{eft})$ $\mathrm{G}$ (reen) sample even though the alternative W(hite) choice had been reinforced after the R(ight) G(reen) sample in reassignment.

For the location-irrelevant group, acquired sample equivalence (i.e., a [Left-Red, Right-Red] and a [LeftGreen, Right-Green] class) predicts that they will prefer the same comparison on left-sample test trials that had been reinforced on the right-sample reassignment trials. Consequently, these pigeons should exhibit higher accuracies in the consistent rather than the inconsistent condition. Finally, the control group was not expected to show a difference between the two test conditions, because their initial training in Experiment 1 could not have produced acquired sample equivalence.

\section{Method}

\section{Subjects and Apparatus}

The same pigeons and apparatus as those in Experiment 1 were used.

\section{Procedure}

After the novel location test in Experiment 1, all pigeons received 5 sessions of refresher training on their respective 0-delay symbolic matching tasks (see Initial Training in Table 2).

Reassignment training. Next, pigeons in the location-relevant and location-irrelevant groups learned to match red and green samples on the right key to blue and white comparisons. Each 96- 
trial session consisted of equal numbers of the four possible trial types ( 2 right-key samples $\times 2$ left vs. center configurations of the comparisons) presented in random order, with the constraint that no trial type occur more than three times in a row. For half of the birds in each group, the white comparison choice was reinforced after red, and the blue comparison choice was reinforced after green; for the remaining birds, the opposite sample-comparison relations were reinforced. Within each group, the matching contingencies for reassignment training were counterbalanced with respect to their hue-line contingencies in Experiment 1. All other procedural details were identical to those previously described.

Each reassignment session for the location-relevant and locationirrelevant pigeons was alternated across days with continued training on their many-to-one (initial training) task from Experiment 1. This alternation continued until each bird correctly matched the right-red and right-green samples to the blue and white comparisons on $90 \%$ or more of the trials for 5 of 6 successive reassignment sessions. One final many-to-one refresher session was then given before testing.

Transfer testing. Ten test sessions followed reassignment (location-irrelevant and location-relevant groups) or the 5 postlocation-test refresher sessions (control group). Each session consisted of 96 trials with blue and white comparisons, 48 baseline trials with red and green samples on the right key, and 48 test trials with red and green samples on the left key. On the left-sample test trials, half of the pigeons in each group obtained food by pecking the same hue comparison that was reinforced following the red and green samples on the right key (consistent test). The remaining pigeons obtained food by pecking the opposite comparison vis-à-vis the comparison reinforced on the baseline trials (inconsistent test). All other procedural details were the same as those previously described.

\section{Results}

The location-irrelevant and location-relevant groups met criterion on the reassignment task in 6.9 and 12.0 sessions, respectively, a nonsignificant difference $[F(1,14)=$ 1.43]. Mean right-sample matching accuracies on the last reassignment session preceding transfer were $96.9 \%$ and 95.3\% correct, respectively. For the control group, mean right-sample accuracy on its last training session preceding transfer was $96.4 \%$ correct. There were no significant differences between groups $[F(2,21)=0.35]$. Average line-comparison accuracies for the left-sample trials on the last refresher (or training) session were 97.4\%, 93.5\%, and $97.1 \%$ correct, respectively, in the three groups. Although accuracy on these trials was significantly lower in the location-relevant group than in the other groups $[F(2,21)=6.10]$, it was still very high.

Figure 3 shows the results from the first test session (top panel) and for all 10 test sessions (bottom panel) for each group. Performances in the consistent condition are shown by the dark bars and solid symbols; performances in the inconsistent condition are shown by the lighter bars and open symbols. Only test-trial accuracy (i.e., accuracy with the left-key samples) is depicted.

First-session accuracy in all three groups was above chance in the consistent condition and below chance in the inconsistent condition. An ANOVA on these data with group and condition as factors showed a significant overall effect of test condition $[F(1,18)=74.97]$, no overall group effect $[F(2,18)=0.01]$, and no group $\times$ test condition interaction $[F(2,18)=0.71]$.

Likewise, with repeated testing, acquisition of the left sample-choice relations in each test condition was gener-
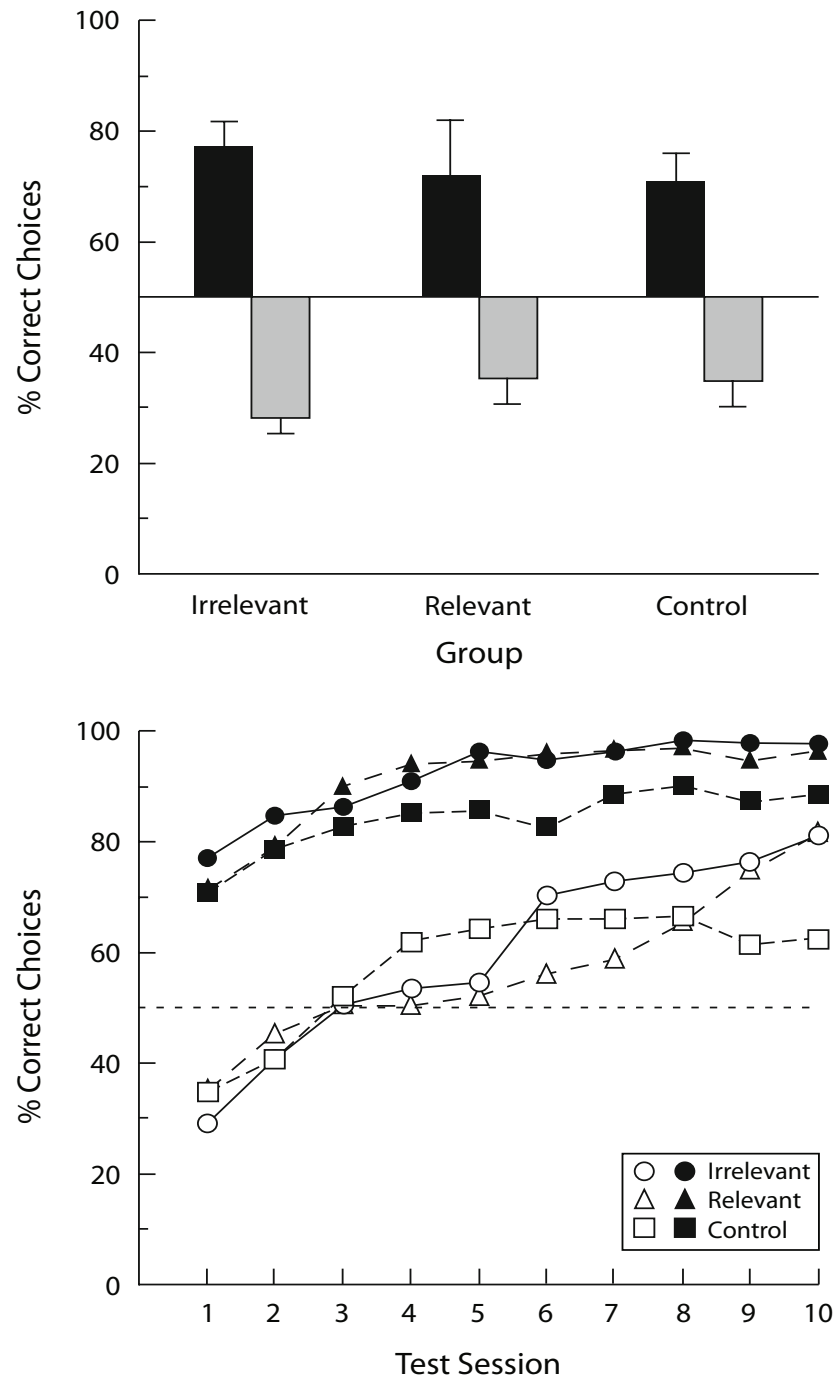

Figure 3. Top panel: Percentage of correct test-trial (left-sample) choices $(+1 S E M)$ for each group on the first transfer session in Experiment 2. Dark and light bars show performance in the consistent and inconsistent test conditions, respectively. Bottom panel: Percentage of correct test-trial (left-sample) choices for each group on all 10 transfer sessions in Experiment 2. Filled and open symbols show performance in the consistent and inconsistent test conditions, respectively.

ally comparable across groups. For the consistent test condition (filled symbols), neither the group effect $[F(2,9)=$ $0.67]$ nor the group $\times$ session interaction $[F(9,81)=$ $0.37]$ were significant. For the inconsistent test condition (open symbols), the group effect was not significant $[F(2,9)=0.09]$, although the group $\times$ session interaction was $[F(9,81)=2.07]$, in large part because of the plateau in the control group's accuracy.

The consistent versus inconsistent difference averaged over all test sessions was significant for the locationirrelevant and location-relevant groups $[F \mathrm{~s}(1,6)=56.72$ and 44.61, respectively], as were the test condition $\times$ session interactions $[F \mathrm{~s}(9,54)=3.45$ and 2.26 , respectively]. Test condition was not significant in the control group 
when averaged over all 10 test sessions $[F(1,6)=4.92]$, but it was over the first 5 sessions $[F(1,6)=9.12]$. The test condition $\times$ session interaction for the control group was significant $[F(9,54)=1.75]$.

Finally, each group maintained very high baseline (right-sample) accuracies throughout testing: $98.4 \%$ and $93.7 \%$ correct, respectively, in the consistent and inconsistent conditions for the location-irrelevant group; $97.3 \%$ and $91.8 \%$ correct, respectively, in the consistent and inconsistent conditions for the location-relevant group; and $95.7 \%$ and $95.5 \%$ correct, respectively, in the consistent and inconsistent conditions for the control group. The differences were not significant for the latter two groups $[F \mathrm{~s}(1,6)=2.86$ and 0.01 , respectively $]$, but it was significant in the location-irrelevant group $[F(1,6)=11.77]$.

\section{Discussion}

Considering the main purpose of Experiment 2, the most notable finding was the absence of acquired sample equivalence in the location-relevant group. If the many-to-one training these pigeons received in Experiment 1 had been sufficient to bring opposing hue samples on different keys into the same class, then they should have performed more accurately in the inconsistent than in the consistent test. Not only did this result fail to materialize, the opposite pattern was obtained: Accuracy was higher in the consistent than in the inconsistent condition.

The location-irrelevant group also exhibited higher accuracy in the consistent test. For them, however, it was fully expected, because their many-to-one task in Experiment 1 was conducive to producing a [Left-Red, RightRed] and a [Left-Green, Right-Green] sample class (cf. Table 2). Besides, the location-irrelevant birds could have simply ignored sample location and attended only to sample hue, as the novel-location test data in Experiment 1 indicate they had learned to do. In actuality, these may not be independent mechanisms: Perhaps acquired equivalence between the same nominal stimulus on left and right keys causes the left-right variation to be ignored.

Another interesting finding was that the control group also showed a consistent $>$ inconsistent difference in testing. From a purely acquired equivalence perspective, these pigeons should have been indifferent to the blue versus white comparisons on their left-sample test trials. Besides, even though they were familiar with the red and green samples and the blue and white comparisons, these stimuli appeared in novel location configurations on the test trials. Nevertheless, their right-sample matching performances transferred to red and green samples on the left key. This contrasts with the finding in Experiment 1 that the control pigeons did not transfer their hue sampleline comparison performance to novel sample locations. Although there are a variety of factors that might account for the discrepant results, seeing red and green at a highly familiar (left-key) test location in this experiment as opposed to a novel (center-key) location in Experiment 1 is probably important, along with the location of the comparison stimuli which will be emphasized next.

\section{GENER AL DISCUSSION}

The two experiments reported here yielded three noteworthy findings. First, symbolic matching in which the reinforced choice following each nominal sample stimulus switched across left and right sample locations (location-relevant group) was acquired as rapidly as when the reinforced choice remained the same (locationirrelevant group). Second, symbolic matching with left- and right-key samples transferred to a novel, center-key location only if those samples occasioned the same comparison choice in training (location-irrelevant group). Transfer did not occur if different, nonconflicting choices were reinforced after left- and right-key samples in training (control group). Third, opposite sample hues appearing at different locations (e.g., left-red and right-green) did not become equivalent, despite a many-to-one (common-comparison) association in training (location-relevant group; see Urcuioli, 2006a). Because the first and second findings have already been fully discussed, this discussion will focus on interpreting the equivalence test results.

The absence of acquired sample equivalence in the location-relevant group is curious in view of the extensive literature on the potency of many-to-one associations in generating sample equivalence classes (e.g., Bovet \& Vauclair, 1998; Edwards, Jagielo, Zentall, \& Hogan, 1982; Spradlin, Cotter, \& Baxley, 1973; Urcuioli \& LionelloDeNolf, 2005). Class membership is typically demonstrated by arranging new contingencies for a subset of samples from each putative class and later showing that performances engendered by those contingencies immediately generalize to the remaining samples (see, e.g., Wasserman et al., 1992; see also Dougher \& Markham, 1994; Goldiamond, 1962; Vaughan, 1988). Here, the putative sample classes for the location-relevant group arising from its many-to-one training in Experiment 1 were [Left-Red, Right-Green] and [Left-Green, Right-Red]. After new comparison choices were then established to the two right-key samples, the expectation was that these new choices would immediately generalize to their corresponding left-key "partners." But the test results in Experiment 2 showed otherwise. The predicted difference between the two test conditions not only failed to materialize but was actually the reverse.

The results from this group raise two separate questions. (1) Why did acquired equivalence fail to develop between samples that ostensibly occasioned the same reinforced choice in training? (2) Why weren't their test performances at chance? (Viz., why did the new choices established to the right-key samples generalize to the same nominal left-key samples?)

An answer to the first question can be gleaned by closer inspection of the training contingencies. Figure 4 shows all eight symbolic matching trials for the location-relevant group organized so that Left-Red and Right-Green sample trials are grouped together (top two rows), as are LeftGreen and Right-Red sample trials (bottom two rows). The organization also presupposes that the reinforced choices 


\section{Common Reinforced Choices}

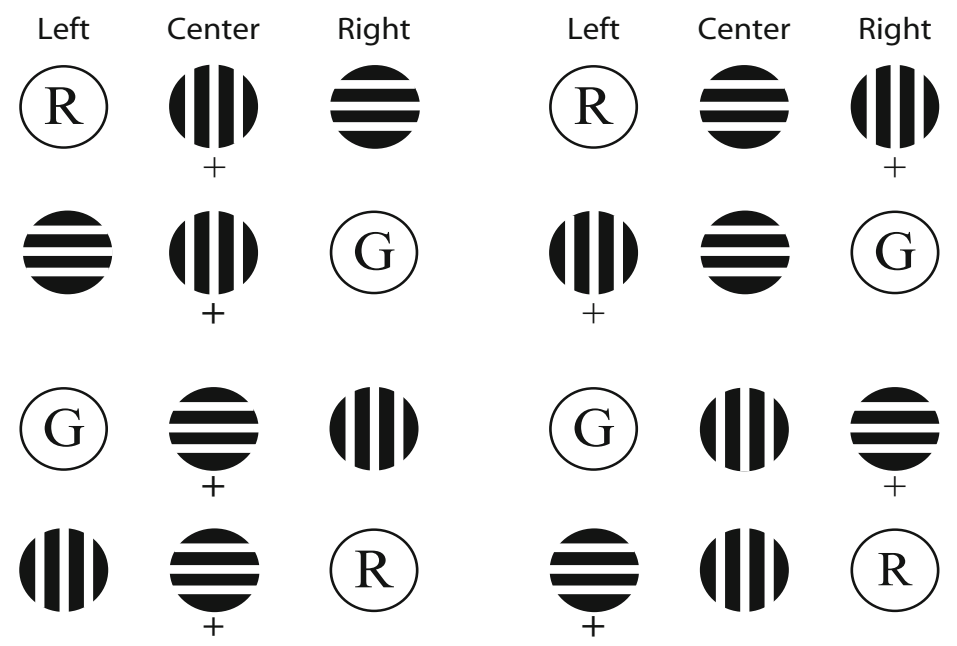

Figure 4. A schematic of the symbolic matching contingencies for the location-relevant group in Experiment 1. R, red sample stimulus; G, green sample stimulus; + , reinforced line-comparison choice.

are not simply vertical versus horizontal lines per se, but vertical and horizontal lines on a particular key. Note that if vertical on the center key is not the same comparison stimulus for pigeons as vertical on the left (or right) key, then only half of the trials with the Left-Red and RightGreen samples actually occasioned the same reinforced choice (and likewise for the Left-Green and Right-Red samples), as shown under "common reinforced choices" in Figure 4. (Vertical-on-the-center-key is the common reinforced choice for the former two samples, and horizontal-on-the-center-key is the common reinforced choice for the latter two samples.)

The remaining trials, however, involved different reinforced choices, as shown on the right side of Figure 4. For example, pecking vertical-on-the-right-key was reinforced after the Left-Red sample, but pecking vertical-on-the-left-key was reinforced after the RightGreen sample. Thus, the Left-Red and Right-Green samples did not always occasion the same comparison choice, nor did the Left-Green and Right-Red samples. Describing these matching contingencies as "many-toone," then, is clearly improper, and the consequent lack of acquired sample equivalence is hardly surprising (Urcuioli \& Lionello-DeNolf, 2005).

This point also applies to the location-irrelevant group. For this group as well, half of the trials with the Left-Red and Right-Red samples and half with the Left-Green and Right-Green samples involved different reinforced comparison choices (e.g., vertical-on-the-right-key after Left-Red, but vertical-on-the-left-key after Right-Red). This result implies that the observed transfer in this group (viz., higher accuracy in the consistent than in the inconsistent test condition) was not due to acquired sample equivalence.
So what explains the above-chance accuracies in the consistent test conditions, and the below-chance accuracies in the inconsistent test conditions? First, unlike the novel-location test in Experiment 1, the samples in the acquired equivalence test appeared at a highly familiar (left-key) location. Second, after reassignment training (location-relevant and location-irrelevant groups) or initial training (control group), pigeons were familiar with the blue and white comparisons at only one of the two locations (the center key) at which they would appear in testing. Their equivalence test performances reflected this. When the comparisons appeared at the familiar location, pigeons chose the same comparison after each left-key sample that had been reinforced after the corresponding right-key sample during reassignment or initial training $83.7 \%$ of the time on average $(75.0 \%, 85.4 \%$, and $90.6 \%$ for the location-relevant, location-irrelevant, and control groups, respectively). By contrast, when the comparisons appeared at the unfamiliar (right-key) location, they chose the same comparison only $50.9 \%$ of the time on average $(61.5 \%, 55.2 \%$, and $35.9 \%$ for the three groups, respectively). Note that this variation in performance is further evidence in support of the analysis developed in Figure 4 - namely, that the functional comparison stimuli should be defined in terms of their location.

In summary, pigeons' performances in two-alternative matching are clearly sensitive to both sample location and comparison location. Their sensitivity to sample location, an effect already established by Lionello and Urcuioli (1998), may slow the rate of matching acquisition even if location is an irrelevant feature. Their sensitivity to comparison location, as documented here, can preclude the development of acquired equivalence between samples 
that ostensibly occasion the same reinforced choice. Together, the data underscore once again the importance of understanding the nature of the functional stimuli in the analysis of conditional discriminations and equivalenceclass formation (McIlvane et al., 2000).

\section{AUTHOR NOTE}

This research was supported by NIMH Grant MH 66915. The author expresses his appreciation to Sarah Michalek and Kate Willaman for their assistance in conducting this research, and Jim Mazur and the anonymous reviewers for their constructive feedback. Correspondence concerning this article should be addressed to P. J. Urcuioli, Department of Psychological Sciences, 703 Third Street, West Lafayette, IN $47907-$ 2081 (e-mail: uche@psych.purdue.edu).

\section{REFERENCES}

Berryman, R., Cumming, W. W., Cohen, L. R., \& Johnson, D. F. (1965). Acquisition and transfer of simultaneous oddity. Psychological Reports, 17, 767-775.

Bovet, D., \& Vauclair, J. (1998). Functional categorization of objects and of their pictures by baboons (Papio anibus). Learning \& Motivation, 29, 309-322.

Bowe, C. A., Miller, J. D., \& Green, L. (1987). Qualities and locations of stimuli and responses affecting discrimination learning of chinchillas (Chinchilla laniger) and pigeons (Columba livia). Journal of Comparative Psychology, 101, 132-138.

Carter, D. E., \& Eckerman, D. A. (1975). Symbolic matching by pigeons: Rate of learning complex discriminations predicted from simple discriminations. Science, 187, 662-664.

Cumming, W. W., \& Berryman, R. (1961). Some data on matching behavior in the pigeon. Journal of the Experimental Analysis of Behavior, 4, 281-284.

Dougher, M. J., \& Markham, M. R. (1994). Stimulus equivalence, functional equivalence, and the transfer of function. In S. C. Hayes, L. J. Hayes, M. Sato, \& K. Ono (Eds.), Behavior analysis of language and cognition (pp. 71-90). Reno, NV: Context Press.

Edwards, C. A., Jagielo, J. A., Zentall, T. R., \& Hogan, D. E. (1982). Acquired equivalence and distinctiveness in matching to sample by pigeons: Mediation by reinforcer-specific expectancies. Journal of Experimental Psychology: Animal Behavior Processes, 8, 244-259.

Goldiamond, I. (1962). Perception. In A. J. Bachrach (Ed.), Experimental foundations of clinical psychology (pp. 280-340). New York: Basic Books.

Grant, D. S., \& Spetch, M. L. (1993). Analogical and nonanalogical coding of samples differing in duration in a choice-matching task in pigeons. Journal of Experimental Psychology: Animal Behavior Processes, 19, 15-25.

IVERSEN, I. (1997). Matching-to-sample performance in rats: A case of mistaken identity? Journal of the Experimental Analysis of Behavior, 68, 27-47.

Iversen, I., Sidman, M., \& Carrigan, P. (1986). Stimulus definition in conditional discriminations. Journal of the Experimental Analysis of Behavior, 45, 297-304.

JENKINS, H. M., \& HARRISON, R. H. (1960). Effects of discrimination training on auditory generalization. Journal of Experimental Psychology, 59, 246-253.

Lionello, K. M., \& UrCuioli, P. J. (1998). Control by sample location in pigeons' matching-to-sample. Journal of the Experimental Analysis of Behavior, 70, 235-251.

Lionello-DeNolf, K. M., \& Urcuioli, P. J. (2000). Transfer of pigeons' matching to sample to novel sample locations. Journal of the Experimental Analysis of Behavior, 73, 141-161.

Mcilvane, W. J., Serna, R. W., Dube, W. V., \& Stromer, R. (2000). Stimulus control topography coherence and stimulus equivalence: Reconciling test outcomes with theory. In J. Leslie \& D. E. Blackman (Eds.), Experimental and applied analysis of human behavior (pp. 85110). Reno, NV: Context Press.
Pearce, J. M. (1987). A model of stimulus generalization in Pavlovian conditioning. Psychological Review, 94, 61-73.

Pearce, J. M. (1994). Similarity and discrimination: A selective review and a connectionist model. Psychological Review, 101, 587-607.

Pearce, J. M., \& Redhead, E. S. (1993). The influence of an irrelevant stimulus on two discriminations. Journal of Experimental Psychology: Animal Behavior Processes, 19, 180-190.

Peterson, G. B., \& Trapold, M. (1982). Expectancy mediation of concurrent conditional discriminations. American Journal of Psychology, 95, 371-380.

RODGER, R. S. (1975). The number of non-zero, post hoc contrasts from ANOVA and error rate: I. British Journal of Mathematical \& Statistical Psychology, 28, 71-78.

Spradlin, J. E., Cotter, V. W., \& BaXley, N. (1973). Establishing a conditional discrimination without direct training: A study of transfer with retarded adolescents. American Journal of Mental Deficiency, 77, 556-566.

UrCUIOLI, P. J. (1996). Acquired equivalences and mediated generalization in pigeons' matching-to-sample. In T. R. Zentall \& P. M. Smeets (Eds.), Stimulus class formation in humans and animals (pp. 55-70). Amsterdam: Elsevier.

UrCuioli, P. J. (2006a). Responses and acquired equivalence classes. In E. A. Wasserman \& T. R. Zentall (Eds.), Comparative cognition: Experimental explorations of animal intelligence (pp. 405-421). New York: Oxford University Press.

UrCUIOLI, P. J. (2006b). When discrimination fails (or at least falters). Journal of Experimental Psychology: Animal Behavior Processes, 32, 359-370.

Urcuioli, P. J., DeMarse, T. B., \& Lionello-DeNolf, K. M. (2001). Assessing the contributions of $\mathrm{S}-\mathrm{O}$ and $\mathrm{R}-\mathrm{O}$ associations to differential-outcome matching through outcome reversals. Journal of Experimental Psychology: Animal Behavior Processes, 27, 239-251.

Urcuioli, P. J., \& Lionello-DeNolf, K. M. (2001). Some tests of the anticipatory mediated generalization model of acquired equivalence in pigeons' many-to-one matching. Animal Learning \& Behavior, 29, 265-280

Urcuioli, P. J., \& Lionello-DeNolf, K. M. (2005). The role of common reinforced comparison responses in acquired sample equivalence. Behavioural Processes, 69, 207-222.

Urcuioli, P. J., Vu, K.-P. L., \& Proctor, R. W. (2005). A Simon effect in pigeons. Journal of Experimental Psychology: General, 134, 93-107.

Urcuioli, P. J., \& Zentall, T. R. (1986). Retrospective coding in pigeons' delayed matching-to-sample. Journal of Experimental Psychology: Animal Behavior Processes, 12, 69-77.

Urcuioli, P. J., Zentall, T. R., Jackson-Smith, P., \& Steirn, J. N. (1989). Evidence for common coding in many-to-one matching: Retention, intertrial interference, and transfer. Journal of Experimental Psychology: Animal Behavior Processes, 15, 264-273.

VAUGHAN, W., JR. (1988). The formation of equivalence sets in pigeons. Journal of Experimental Psychology: Animal Behavior Processes, 14, 36-42.

Wagner, A. R., Logan, F. A., Haberlandt, K., \& Price, T. (1968). Stimulus selection in animal discrimination learning. Journal of Experimental Psychology, 76, 171-180.

Wasserman, E. A., DeVolder, C. L., \& Coppage, D. J. (1992). Nonsimilarity-based conceptualization in pigeons. Psychological Science, 3, 374-379.

Wilkie, D. M., Jacobs, W. J., \& TaKaI, R. M. (1985). Pigeons match location of sample more accurately than color of sample. Bulletin of the Psychonomic Society, 23, 156-159.

Williams, D. A., Butler, M. M., \& Overmier, J. B. (1990). Expectancies of reinforcer location and quality as cues for a conditional discrimination. Journal of Experimental Psychology: Animal Behavior Processes, 16, 3-13.

(Manuscript received May 2, 2007; revision accepted for publication June 28,2007 .) 